\title{
Perinatal outcome according to chorionicity in twins - a Polish multicenter study
}

\author{
Katarzyna Kosińska-Kaczyńska ${ }^{1}$, Iwona Szymusik ${ }^{1}$, Dorota Bomba-Opoń ${ }^{1}$, Anita Olejek ${ }^{2}$, \\ Helena Sławska ${ }^{2}$, Mariusz Zimmer ${ }^{3}$, Michał Pomorski ${ }^{3}$, Grzegorz Bręborowicz ${ }^{4}$, \\ Krzysztof Drews ${ }^{5}$, Agnieszka Seremak-Mrozikiewicz ${ }^{5}$, Marta Szymankiewicz ${ }^{6}$, Tomasz Pikuła ${ }^{6}$, \\ Jan Oleszczuk ${ }^{7}$, Jolanta Patro-Małysza7 , Beata Marciniak7 , Mirosław Wielgoś ${ }^{1}$ \\ ${ }^{1} 1^{\text {st }}$ Department of Obstetrics and Gynecology, Medical University of Warsaw, Poland \\ ${ }^{2}$ Department of Gynecology, Obstetrics and Oncological Gynecology, Medical University of Silesia, Katowice, Poland \\ ${ }^{3} 2^{\text {nd }}$ Department of Gynecology and Obstetrics, Wroclaw Medical University, Wroclaw, Poland \\ ${ }^{4}$ Department of Perinatology and Gynecology, Poznan University of Medical Sciences, Poznan, Poland \\ ${ }^{5}$ Department of Perinatology and Women's Diseases, Poznan University of Medical Sciences, Poznan, Poland \\ ${ }^{6}$ Department of Neonatology, Poznan University of Medical Sciences, Poznan, Poland \\ ${ }^{7}$ Department of Obstetrics and Perinatology, Medical University of Lublin, Poland
}

\begin{abstract}
Objectives: The aim of the study was to analyze the perinatal outcome of twin gestations and estimate the influence of chorionicity on the outcome in a large cohort of twin pregnancies in Poland.

Material and methods: A retrospective analysis of 465 twin deliveries in 6 Polish centers in 2012 was conducted. Baseline characteristics, the course of pregnancy and labor, as well as the neonatal outcome were analyzed in the study group and according to chorionicity.

Results: A total of 356 twin pregnancies were dichorionic (DC group) (76.6\%), and 109 were monochorionic (MC group) (23.4\%). There were no differences in the occurrence of pregnancy complications according to chorionicity, except for IUGR of at least one fetus (MC $43.1 \%$ vs. DC 34.6\%; $\mathrm{p}=0.003$ ). $66.5 \%$ of the women delivered preterm, significantly more in the MC group (78\% vs. 62.9\%; $p=0.004)$. Cesarean delivery was performed in 432 patients $(92.9 \%)$. Mean neonatal birthweight was statistically lower in the MC group (2074 g vs. $2370 \mathrm{~g} ; \mathrm{p}<0.001)$. Perinatal mortality of at least one twin was $4.3 \%$ ( $2.8 \%$ in the DC group vs. 9.2\% in the MC group; $\mathrm{p}=0.004$ ). Neonatal complications, including NICU admission, respiratory disorders, and infections requiring antibiotic therapy, were significantly more often observed among the MC twins.

Conclusions: The overall perinatal outcome in the presented subpopulation of Polish twins and its dependence on chorionicity is similar to the reports in the literature. Nevertheless, the rates of preterm and cesarean deliveries remain higher. It seems that proper counselling of pregnant women and education of obstetricians may result in reduction of these rates. Key words: perinatal outcome, twin pregnancy, chorionicity, perinatal mortality, cesarean section
\end{abstract}

Ginekologia Polska 2016; 87, 5: 384-389

\section{INTRODUCTION}

The rate of multiple pregnancies has been rising worldwide. In the United Stated of America, the number of twin deliveries has increased by $70 \%$ since 1980s [1]. According to the National Vital Statistics Report for Births, the twin delivery rate was 33.7 per 1000 total births in 2013 [2]. A similar trend is observed all around the world. In Poland, the rate of twin deliveries increased by $46 \%$ between 2002 and 2010 [3], reaching 1.3\% in 2013 [4]. The observed trend is the consequence of the prevalence of assisted reproductive technologies (ART), as well as delayed childbearing. Stimulation of ovulation with clomiphene citrate carries an $8 \%$ risk of multiple pregnancy, while the use of gonadotropins increases the risk to $20 \%$. As far as in vitro fertilization is 
concerned, multiple pregnancy rates vary with the number of embryos transferred, reaching $20 \%$ and $25 \%$ in case of a double and triple embryo transfer, respectively [5]. Transferring more than 2 embryos is no longer recommended due to very high prevalence of multiple gestations. The overall increasing trend concerns mainly dizygotic twinning and is also influenced by race (1/1000 births in Japan and almost 50/1000 births in some parts of Nigeria), parity (2\% in $5^{\text {th }}$ pregnancy) and maternal age (2\% at the age of 35 ) [6]. The rate of monozygotic twins remains rather stable ( 3 to $5 / 1000$ births worldwide) [6].

Twins have a three to seven-fold higher risk of perinatal mortality and morbidity than singletons $[7,8]$. Worse perinatal outcome is usually assigned to monochorionic twins and is the consequence of unique placental structure and higher percentage of preterm deliveries. Large studies on twins are frequently based on data from national twin registries. Unfortunately, there is no twin registry in Poland. To the best of our knowledge, there are no national published data on the perinatal outcome of twin pregnancies in Poland, apart from studies concerning results from single departments.

The aim of our study was to analyze the perinatal outcome of twin gestations and estimate the influence of chorionicity on the outcome in a large cohort of twin pregnancies in Poland.

\section{MATERIAL AND METHODS}

A retrospective analysis of medical records of twin deliveries in 2012 in five tertiary university obstetric departments, located in different provinces of Poland, was conducted. The following centers were included: $1^{\text {st }}$ Department of Obstetrics and Gynecology, Medical University of Warsaw (Warsaw), $2^{\text {nd }}$ Department of Gynecology and Obstetrics, Wroclaw Medical University (Wroclaw), Department of Obstetrics and Perinatology, Medical University of Lublin (Lublin), Department of Gynecology, Obstetrics and Oncological Gynecology, Medical University of Silesia (Bytom), Department of Perinatology and Women's Diseases, Poznan University of Medical Sciences (Poznan), and Department of Perinatology and Gynecology, Poznan University of Medical Sciences (Poznan).

All pregnancies were dated according to the last menstrual period and verified by the crown-rump length measured in the first trimester. Chorionicity was established based on the first trimester ultrasound scan. Baseline characteristics of the patients, the course of pregnancy and labor, as well as the neonatal outcome were analyzed in the study group and further evaluated in relation to chorionicity.

Intrauterine fetal demise (IUD) was diagnosed when fetal demise occurred at 22 completed weeks of gestation or later. Early neonatal death was defined as the death of a newborn (weighing $>500 \mathrm{~g}$ and born after 22 weeks of gestation) within the first seven days of life. Perinatal mortality was defined as stillbirth and early neonatal mortality jointly. Mean birthweight and newborn general condition evaluated with the Apgar score were analyzed (Apgar score: 8-10 points - good, 4-7 - average, $0-3$ - bad general condition). Neonatal outcome included short-term morbidity (respiratory complications, neonatal intensive care unit (NICU) admissions, infections requiring intravenous antibiotic therapy, intraventricular hemorrhage grade 3 or 4, necrotizing enterocolitis (NEC), and hyperbilirubinemia requiring phototherapy). Respiratory complications were defined as the occurrence of respiratory distress syndrome (RDS), bronchopulmonary dysplasia, the need for mechanical ventilation or continuous positive airway pressure. Twin-to-twin transfusion syndrome (TTTS) was diagnosed according to Quintero's criteria [9]. Birthweight discordance was defined as $25 \%$ or greater difference in birthweights, with respect to the larger twin. Intrauterine fetal growth restriction (IUGR) was defined as an estimated fetal weight less than the $10^{\text {th }}$ percentile during an ultrasound scan. Steroid therapy in imminent preterm delivery consisted of betamethasone ( 2 doses of $12 \mathrm{mg}$ ) or dexamethasone ( 4 doses of $6 \mathrm{mg}$ ), administered during 48 hours between 24 and 34 weeks of gestation.

Statistical analysis was performed with Mann-Whitney U-test for continuous variables and chi-squared test for categorical variables. Logistic regression analysis was conducted to investigate the impact of individual factors on the neonatal outcome. Statistica 10.0 software was used for statistical analyses. The $p$-value of $<0.05$ was considered as significant and all tests were two-tailed.

\section{RESULTS}

The study group consisted of 465 patients who delivered twins. As there were 5048 twin deliveries in Poland in 2012, the study group accounted for $9.2 \%$ of the whole twin Polish population [CSO 2013]. A total of 356 twin pregnancies were dichorionic (DC group) (76.6\%), and 109 were monochorionic (MC group) (23.4\%), including 8 monochorionic monoamniotic twins (1.7\%).

Baseline characteristics of the patients, as well as the course of pregnancy and delivery in the whole group and in relation to chorionicity are presented in Table 1 . There were no differences in the occurrence of pregnancy complications according to chorionicity, except for IUGR of at least one twin, which occurred significantly more often in the MC group. The occurrence of TTTS was $7.3 \%$ of the MC group. Taking into account the entire study population, $66.5 \%$ of the women delivered before 37 weeks of gestation, significantly more women in the MC than the DC group. The incidence of extremely preterm birth before 28 gestational weeks was similar in both groups. However, significantly 
Table 1. Baseline characteristics, pregnancy complications and the way of delivery in the study group and in DC and MC groups

\begin{tabular}{|c|c|c|c|c|}
\hline & $\begin{array}{c}\text { Total } \\
n=465\end{array}$ & $\begin{array}{c}\text { Dichorionic } \\
n=356\end{array}$ & $\begin{array}{c}\text { Monochorionic } \\
n=109\end{array}$ & \\
\hline & $\begin{array}{l}\text { Mean (SD)/ } \\
\text { /number (\%) }\end{array}$ & $\begin{array}{l}\text { Mean (SD)/ } \\
\text { /number (\%) }\end{array}$ & $\begin{array}{l}\text { Mean (SD)/ } \\
\text { /number (\%) }\end{array}$ & $\mathrm{p}$ (DC vs. MC) \\
\hline Maternal age & $30.7(4.7)$ & $31(5.6)$ & $29.6(5.1)$ & 0.9 \\
\hline Primiparity & $294(63.2 \%)$ & $231(64.9 \%)$ & $63(57.8 \%)$ & 0.2 \\
\hline $\begin{array}{l}\text { Multiparity } \\
\begin{array}{l}1 \\
2 \\
>2\end{array}\end{array}$ & $\begin{array}{c}171(36.8 \%) \\
131 \\
25 \\
15\end{array}$ & $\begin{array}{c}125(35.1 \%) \\
97 \\
18 \\
10\end{array}$ & $\begin{array}{c}46(42.2 \%) \\
34 \\
7 \\
5\end{array}$ & 0.2 \\
\hline GDM & $42(9 \%)$ & $32(9 \%)$ & $10(9.2 \%)$ & 1 \\
\hline $\mathrm{PH}$ & 49 (10.5\%) & $37(10.4 \%)$ & $12(11 \%)$ & 1 \\
\hline PPROM & $116(25 \%)$ & $85(23.9 \%)$ & $31(28.4 \%)$ & 0.3 \\
\hline Pregnancy cholestasis & $26(5.6 \%)$ & $20(5.6 \%)$ & $6(5.5 \%)$ & 0.9 \\
\hline IUGR of at least 1 twin & $170(36.6 \%)$ & $123(34.6 \%)$ & $47(43.1 \%)$ & 0.003 \\
\hline TTTS & & & $8(7.3 \%)$ & \\
\hline Gestational age at delivery (wks) & $34.9(3.1)$ & $35.3(2.7)$ & $33.7(3.6)$ & $<0.001$ \\
\hline Delivery $<37$ wks & $309(66.5 \%)$ & $224(62.9 \%)$ & $85(78 \%)$ & 0.004 \\
\hline$<28$ wks & $19(4.1 \%)$ & $12(3.4 \%)$ & $7(6.4 \%)$ & 0.2 \\
\hline$<30$ wks & $27(5.8 \%)$ & $13(3.7 \%)$ & $14(12.8 \%)$ & 0.002 \\
\hline$<32$ wks & $52(11.2 \%)$ & $27(7.6 \%)$ & $25(22.9 \%)$ & 0.0004 \\
\hline$<34$ wks & $96(20.7 \%)$ & $58(16.3 \%)$ & $38(34.9 \%)$ & 0.00007 \\
\hline $34-36$ wks & $213(45.8 \%)$ & $166(46.6 \%)$ & $47(43.1 \%)$ & 0.5 \\
\hline Spontaneous preterm delivery & $186(60.2 \%)$ & $131(58.5 \%)$ & $55(64.7 \%)$ & 0.4 \\
\hline Cesarean section & $432(92.9 \%)$ & $331(93 \%)$ & $101(92.7 \%)$ & 1 \\
\hline Vaginal delivery & $31(6.7 \%)$ & $23(5.4 \%)$ & $8(7.3 \%)$ & 0.8 \\
\hline Cesarean section on the second twin & $2(0.4 \%)$ & $2(0.6 \%)$ & 0 & 1 \\
\hline Cesarean section $>37$ wks & $141 / 156(90.4 \%)$ & $119 / 132(90.2 \%)$ & $22 / 24(91.7 \%)$ & 1 \\
\hline
\end{tabular}

SD - standard deviation; DC - dichorionic; MC — monochorionic; wks - weeks of gestation; GDM - gestational diabetes; PH — pregnancy hypertension or preeclampsia; IUGR — intrauterine growth restriction; TTTS - twin-to-twin transfusion syndrome

more MC than DC twins were delivered before 30, 32 and 34 weeks of gestation. The majority of preterm deliveries in both groups were those between 34 and $36+6$ gestational weeks (late preterm), and the incidence did not differ significantly between the groups. A total of 214 (46\%) women received a course of steroid therapy during pregnancy due to imminent preterm delivery (153 in the DC group (42.9\%) vs. 61 in the MC group (56\%); $p=0.02$ ). In the whole study population, 31 patients delivered vaginally (6.7\%), $432 \mathrm{had}$ cesarean delivery (92.9\%), and there were 2 cases of cesarean sections performed on the second fetus after vaginal delivery of the first one. The most frequent indication for cesarean delivery were: presentation other than vertex of the first fetus (109; 25.2\%), malpresentation of the second fetus $(53 ; 12.3 \%)$, fetal distress $(61 ; 14.1 \%)$, history of one cesarean section $(48 ; 11.1 \%)$, history of two or more previous cesarean deliveries $(19 ; 4.4 \%)$ and lack of informed consent for vaginal delivery in ART $(113 ; 26.2 \%)$, or monochorionic pregnancies $(89 ; 20.6 \%)$.
Neonatal outcomes in the study group and also in relation to chorionicity are presented in Table 2. Mean neonatal birthweight was statistically lower in the MC group, both of the first and the second twin. Significantly more twins were born in good general condition evaluated with the Apgar score in the DC group. The overall perinatal mortality of at least one twin was $4.3 \%$ (2.8\% in the DC group vs. $9.2 \%$ in the MC group; $p=0.004)$. There were significantly more stillbirths in the MC group. In both groups IUD occurred in chorioamnionitis due to premature rupture of membranes and IUGR, while in the MC groups there were also 2 cases of IUD in the course of TTTS. Early neonatal death occurred also more often in the MC twins, but the difference was not statistically significant. In the DC group, there were 3 cases of the death of one newborn (born at 23, 26 and 31 gestational weeks) and 1 case of the death of both twins (born at 22 weeks). In the MC group, both twins died during the first 7 days of life in all 3 cases (born at 22, 25 and 28 weeks). The causes of neonatal death included severe prematurity, 
Table 2. Neonatal outcome in the study group and according to chorionicity

\begin{tabular}{|c|c|c|c|c|}
\hline Newborns general condition & $\begin{array}{c}\text { Total } \\
\mathrm{n}=917\end{array}$ & $\begin{array}{c}\text { Dichorionic } \\
n=706\end{array}$ & $\begin{array}{c}\text { Monochorionic } \\
n=211\end{array}$ & \\
\hline & $\begin{array}{l}\text { Mean (SD)/ } \\
\text { /number (\%) }\end{array}$ & $\begin{array}{l}\text { Mean (SD)/ } \\
\text { /number (\%) }\end{array}$ & $\begin{array}{l}\text { Mean (SD)/ } \\
\text { /number (\%) }\end{array}$ & $\begin{array}{c}p \\
\text { (DC vs. MC) }\end{array}$ \\
\hline $\begin{array}{l}\text { Neonatal birth weight [g] } \\
\text { first twin } \\
\text { second twin }\end{array}$ & $\begin{array}{l}2302(609) \\
2366(590) \\
2237(622)\end{array}$ & $\begin{array}{l}2370(577) \\
2438(554) \\
2302(592)\end{array}$ & $\begin{array}{l}2074(658) \\
2128(642) \\
2018(672)\end{array}$ & $\begin{array}{l}<0.001 \\
<0.001 \\
<0.001\end{array}$ \\
\hline $\begin{array}{l}1{ }^{\text {st }} \min \text { Apgar score } \\
8-10 \\
4-7 \\
0-3\end{array}$ & $\begin{array}{c}705(76.9 \%) \\
168(18.3 \%) \\
48(4.8 \%)\end{array}$ & $\begin{array}{l}567(80.3 \%) \\
119(16.9 \%) \\
23(2.8 \%)\end{array}$ & $\begin{array}{l}138(65.4 \%) \\
49(23.2 \%) \\
25(11.4 \%)\end{array}$ & $\begin{array}{c}<0.001 \\
0.004 \\
<0.001\end{array}$ \\
\hline $\begin{array}{l}5^{\text {th }} \min \text { Apgar score } \\
8-10 \\
4-7 \\
0-3\end{array}$ & $\begin{array}{l}818(89.2 \%) \\
75(8.2 \%) \\
28(2.6 \%)\end{array}$ & $\begin{array}{l}649(91.6 \%) \\
47(6.6 \%) \\
13(1.8 \%)\end{array}$ & $\begin{array}{c}169(80.1 \%) \\
28(13.3 \%) \\
15(6.6 \%)\end{array}$ & $\begin{array}{l}<0.001 \\
0.002 \\
<0.001\end{array}$ \\
\hline Neonatal complications of at least one twin & $\begin{array}{c}\text { Total } \\
n=464\end{array}$ & $\begin{array}{c}\text { Dichorionic } \\
n=356\end{array}$ & $\begin{array}{c}\text { Monochorionic } \\
n=108\end{array}$ & \\
\hline Discordance $\geq 25 \%$ & $58(12.5 \%)$ & $40(11.2 \%)$ & $18(16.7 \%)$ & 0.1 \\
\hline Very low birth weight $(<1500 \mathrm{~g})$ & $64(9.9 \%)$ & $43(12.1 \%)$ & $21(19.4 \%)$ & 0.057 \\
\hline NICU & $144(31 \%)$ & $97(27.3 \%)$ & $47(43.1 \%)$ & 0.002 \\
\hline Respiratory disorders & $161(34.6 \%)$ & $113(31.7 \%)$ & $48(44.4 \%)$ & 0.02 \\
\hline IVH III or IV & $14(3 \%)$ & $11(3.1 \%)$ & $3(2.8 \%)$ & 1 \\
\hline Antibiotic therapy & $179(38.5 \%)$ & $124(34.8 \%)$ & $55(50.9 \%)$ & 0.005 \\
\hline NEC & $8(9.7 \%)$ & $8(2.3 \%)$ & 0 & 0.2 \\
\hline Phototherapy & $170(36.6 \%)$ & $122(34.3 \%)$ & $48(44.4 \%)$ & 0.07 \\
\hline Congenital anomalies & $42(9.1 \%)$ & $29(8.1 \%)$ & $13(12 \%)$ & 0.09 \\
\hline
\end{tabular}

SD - standard deviation; DC — dichorionic; MC — monochorionic; discordance $\geq 25 \%$ - birth weight discordance $\geq 25 \%$ with respect to the larger twin; NICU — Neonatal Intensive Care Unit admission; IVH — intraventricular hemorrhage; NEC — necrotizing enterocolitis

Table 3. Perinatal mortality in twins

\begin{tabular}{|c|c|c|c|c|c|}
\hline & $\begin{array}{c}\text { Total } \\
n=465\end{array}$ & $\begin{array}{l}\text { Dichorionic } \\
n=356\end{array}$ & $\begin{array}{c}\text { Monochorionic } \\
n=109\end{array}$ & OR $(95 \% \mathrm{Cl})$ & $\mathrm{p}$ (DC vs. MC) \\
\hline Perinatal mortality & $20(4.3 \%)$ & $10(2.8 \%)$ & $10(9.2 \%)$ & $3.5(1.3-9.4)$ & 0.004 \\
\hline IUD & $13(2.8 \%)$ & $\begin{array}{c}6(1.7 \%) \\
6-\text { one twin }\end{array}$ & $\begin{array}{c}7(6.4 \%) \\
6 \text { - one twin } \\
1-\text { both twins }\end{array}$ & $4(1.2-13.8)$ & 0.02 \\
\hline Early neonatal mortality & $7(1.5 \%)$ & $\begin{array}{c}4(1.1 \%) \\
3-\text { one twin } \\
1-\text { both twins }\end{array}$ & $\begin{array}{l}3 / 108(2.8 \%) \\
3 \text { - both twins }\end{array}$ & $0.4(0.1-2.3)$ & 0.2 \\
\hline
\end{tabular}

OR — odds ratio; $95 \% \mathrm{Cl}$ - confidence interval; IUD — intrauterine fetal demise

IUGR, infection (including one case of sepsis), and congenital heart defect (tetralogy of Fallot). Monochorionicity increased the risk of overall perinatal mortality (OR 3.5) and stillbirth (OR 4), but not early neonatal mortality (Table 3).

MC twins significantly more often experienced neonatal complications, including NICU admissions, respiratory disorders and infections requiring antibiotic therapy. Jaundice requiring phototherapy was also more frequent in the MC group, but the difference was not statistically significant. Congenital anomalies, mostly heart defects, occurred more often in the MC twins, but without statistical significance.

\section{DISCUSSION}

To the best of our knowledge, this has been the first published multicenter cohort study on perinatal outcome in twins in Poland. The results show that mean gestational age at delivery was significantly lower in the MC than in the DC group (33.7 vs. 35.3 weeks), which is similar to data presented by other authors [8, 10-13]. According to the literature, the rates of deliveries before 37 weeks of gestation in twins vary from 52 to $60 \%[14,15]$. In the Preterm Prediction Study, $54.4 \%$ of the twins were delivered before $37,32 \%$ before 35 and $8.8 \%$ before 32 weeks of gestation 
[16]. According to Burgess, $60 \%$ of DC and $65 \%$ of $M C$ twins are born preterm [17]. In our study, the rate of preterm deliveries in the DC group was similar, while in the MC group it was significantly higher (78\%). There were no statistically significant differences in the rate of preterm labors before 28 gestational weeks and in the group of late preterm deliveries. Nevertheless, labor before 30, 32 and 34 completed weeks occurred significantly more often in the MC group. Similar results were presented by Leduc. In his study, the rate of preterm deliveries before 34 weeks of gestation was significantly higher in the MC group, while those before 30 weeks of gestation did not differ by chorionicity [10].

According to the literature, the rate of cesarean deliveries in twin gestations is higher than in singletons - it varies between 43 and $64 \%$ and does not differ significantly between DC and MC twins [10,13,14, 17-19]. The results of the Randomized Trial of Planned Cesarean or Vaginal Delivery for Twin Pregnancy were published in 2013: 2804 women in twin pregnancies between 32 weeks 0 days and 38 weeks 6 days of gestation and with the first twin in the cephalic presentation were randomized for planned cesarean section or planned vaginal delivery. There were no differences in fetal, neonatal, and maternal mortality or serious morbidity, depending on the delivery mode after 32 weeks of gestation [20]. Hoffmann also proved no increased risk for poor outcome in $\mathrm{MC}$ twins with intended vaginal delivery [21]. As an elective cesarean section does not bring any benefit to the perinatal outcome, nowadays the indications for a planned operative delivery in twins are fewer. The non-cephalic presentation of the first twin is one of the most common indications, also in our study [14]. The Term Breech Trial proved the reduction in perinatal mortality and morbidity by planned cesarean section for breech [22]. The vertex-non-vertex presentation occurs in about $40 \%$ of all twins. Furthermore, about $20 \%$ of vertex second twins change their presentation spontaneously after the delivery of the first twin [23]. If one twin is vertex and the other is breech, the occurrence of the locked twin during labor is one of the major concerns. It is a rare but very serious complication, with the mortality rate of about $30-40 \%$ [23]. Ahmed [24] proved that successful external cephalic version or internal podalic version during vaginal delivery of the second non-vertex twin is not associated with compromised neonatal outcome in comparison to elective cesarean delivery.

In our study, the cesarean delivery rate was much higher than presented in the literature. Over $90 \%$ of all twins, both DC and MC, were delivered by cesarean section. Even term twin deliveries were cesarean in more than $90 \%$, while the respective rates reported in the literature are much lower. According to Loriore, $73-77 \%$ of term twins are delivered vaginally [7]. Our results are probably a consequence of the guidelines published by the Polish Gynecological Society. Two of the three most common indications for cesarean delivery in our study were pregnancy after assisted reproductive technologies (ART) or monochorionic twin pregnancy. According to the Polish guidelines, in both cases maternal written consent for the trial of vaginal labor is obligatory [25]. Due to the lack of consent, monochorionicity or ART may be the only indication for an operative delivery. It seems exceedingly important to counsel pregnant women properly, so that the decision made by the patient is fully informed and based on factual data.

In the present study, neonatal complications occurred more often in the MC group, with respiratory disorders, infections, and excessive jaundice as the most frequent occurrences. Also, $31 \%$ of all newborns were hospitalized at NICU, significantly more MC than DC twins. According to the literature, the rate of NICU admissions of twins is similar to our results and reaches about $20-30 \%$ in DC and $30-40 \%$ in MC twins [7, 8, 10, 14]. Twins have also a 10-fold increase in the risk of intrauterine growth restriction as compared to singletons [6]. In our study, weight discordance of $25 \%$ or more was observed in over $15 \%$ of MC and over $10 \%$ of DC twins. The risk of delivering at least one twin with very low birthweight was similar. These results are similar to the previous reports in the literature $[10,12,18]$. Burgess identified the risk of perinatal mortality and morbidity in twins according to gestational age. The nadir of composite morbidity was observed at 37 gestational weeks for DC and 36 gestational weeks for MC twins [17]. Higher morbidity rates in the late preterm than in the term group were also observed in our previously published data concerning the same study group [26].

Twin pregnancies have higher rates of neonatal mortality and stillbirth. The overall perinatal mortality in our study was $4.3 \%$. MC twins have at least two-fold higher risk of this complication than DC [7]. According to Hack, perinatal mortality above (after) 20 weeks of gestation reaches $11.6 \%$ in $M C$ and $5 \%$ in DC pregnancies [8]. Similar results were reported in our study. Overall perinatal mortality and IUD rates were significantly higher in the MC group, while early neonatal mortality was higher, but without statistical significance. The risk of IUD in twins was analyzed in the literature and ranged from 2.5 to $6 \%[11,27,28]$.

Monochorionicity is associated with about 3- to 4-fold higher risk of IUD than dichorionicity $[12,13,29]$. The above relationship was also observed in our study. In DC twins, the risk of stillbirth remains below 3.5 per 1000 between 26 and 37 weeks of gestation [8, 30, 31]. In MC twins it is significantly higher (6.5 per 1000 according to Dias) and remains stable between 26 and 36 gestational weeks and afterwards it increases [30,31]. The nadir of perinatal mortality is observed at 36 completed weeks for MC and 37 completed weeks for 
DC twins [17]. Therefore, it seems rational to have expectant management until 37 weeks in uncomplicated MC twins and until 37-38 weeks in uncomplicated DC twins [31].

\section{CONCLUSIONS}

The overall perinatal outcome in the presented subpopulation of Polish twins and its dependence on chorionicity is similar to the reports in the literature. Nevertheless, the rates of preterm and cesarean deliveries are higher. It seems that proper counselling of pregnant women and education of obstetricians may result in reduction of these rates.

\section{Conflict of interest}

The authors declare that there is no conflict of interest regarding the publication of this article.

\section{REFERENCES}

1. Martin JA, Hamilton BE, Sutton PD, [et al.]. Births: Final data for 2007. National Vital Statistics Report. 2010, 58, 1-85.

2. Martin JA, Hamilton BE, Osterman MJK, [et al.]. Births: Final data for 2013. National Vital Statistics Report. 2015, 64 (1), 1-68.

3. Central Statistical Office. Demographic yearbook of Poland. Warsaw, 2012

4. Central Statistical Office. Demographic yearbook of Poland. Warsaw, 2014.

5. Umstad MP, Gronow MJ. Multiple pregnancy: a modern epidemic? Med J Aust. 2003, 178, 613-615.

6. Rao A, Sairam S, Shehata H. Obstetric complications of twin pregnancies. Best Pract Res Clin Obstet Gynaecol. 2004, 18 (4), 557-576.

7. Lopriore $E$, Stroeken $H$, Sueters $M$, [et al.]. Term perinatal mortality and morbidity in monochorionic and dichorionic twin pregnancies: a retrospective study. Acta Obstet Gynecol Scand. 2008, 87 (5), 541-545.

8. Hack KE, Derks JB, Elias SG, [et al.]. Increased perinatal mortality and morbidity in monochorionic versus dichorionic twin pregnancies: clinical implications of a large Dutch cohort study. BJOG. 2008, 115, 58-67.

9. Ropacka-Lesiak M, Breborowicz GH. Current recommendations for the management of TTTS. Ginekol Pol. 2014, 85 (8), 619-623.

10. Leduc L, Takser L, Rinfret D. Persistance of adverse obstetric and neonatal outcomes in monochorionic twins after exclusion of disorders unique to monochorionic placentation. Am J Obstet Gynecol. 2005, 193 (5), 1670-1675.

11. McPherson JA, Odibo AO, Shanks AL, [et al.]. Impact of chorionicity on risk and timing of intrauterine fetal demise in twin pregnancies. $A m$ J Obstet Gynecol. 2012, 207 (3), 190.e1-6.

12. Glinianaia SV, Obeysekera MA, Sturgiss S, [et al.]. Stillbirth and neonatal mortality in monochorionic and dichorionic twins: a population-based study. Hum Reprod. 2011, 26 (9), 2549-2557.
13. Sullivan $\mathrm{AE}$, Hopkins $\mathrm{PN}$, Weng $\mathrm{H}-\mathrm{I}$, [et al.]. Delivery of monochorionic twins in the absence of complications: analysis of neonatal outcomes and costs. Am J Obstet Gynecol. 2012, 206, 257.e1-7.

14. Garabedian C, Poulain C, Duhamel A, [et al.]. Intrapartum management of twin pregnancies: are uncomplicated monochorionic pregnancies more at risk of complications than dichorionic pregnancies? Acta Obstet Gynecol Scand. 2015, 94 (3), 301-307.

15. Tarter JG, Khoury A, Barton JR, [et al.]. Demographic and obstetric factors influencing pregnancy outcome in twin gestations. Am J Obstet Gynecol. 2002, 186 (5), 910-912.

16. Goldenberg RL, lams JD, Miodovnik $M$, [et al.]. The preterm prediction study: risk factors in twin gestations. National Institute of Child Health and Human Development Maternal-Fetal Medicine Units Network. Am J Obstet Gynecol. 1996, 175 (4 Pt 1), 1047-1053.

17. Burgess JL, Unal ER, Nietert PJ, [et al.]. Risk of late-preterm stillbirth and neonatal morbidity for monochorionic and dichorionic twins. Am J Obstet Gynecol. 2014, 210 (6), 578.e1-9.

18. Victoria A, Mora G, Arias F. Perinatal outcome, placental pathology, and severity of discordance in monochorionic and dichorionic twins. Obstet Gynecol. 2001, 97 (2), 310-315.

19. Weisz B, Hogen L, Yinon Y, [et al.]. Mode of delivery and neonatal outcome in uncomplicated monochorionic twin pregnancies. J Matern Fetal Neonatal Med. 2012, 25 (12), 2721-2724.

20. Barrett JF, Hannah ME, Hutton EK, [et al.]. A randomized trial of planned cesarean or vaginal delivery for twin pregnancy. NEnglJ Med. 2013, 369 (14), 1295-1305.

21. Hoffmann E, Oldenburg A, Rode L, [et al.]. Twin births: cesarean section or vaginal delivery? Acta Obstet Gynecol Scand. 2012, 91 (4), 463-469.

22. Hannah ME, Hannah WJ, Hewson S, [et al.]. Term Breech Trial Collaborative Group. Planned caesarean section versus planned vaginal birth for breech presentation at term: a randomized multicenter trial. Lancet. 2000, 356, 1375-1383.

23. Barrett JF. Twin delivery: method, timing and conduct. Best Pract Res Clin Obstet Gynaecol. 2014, 28 (2), 327-338.

24. Ahmed F, Naeem N, Yasir S. Management of nonvertex second twin. J Obstet Gynaecol India. 2013, 63 (3), 177-181.

25. Polish Gynecological Society Guidelines. Caesarean Section. Ginekologia po Dyplomie. 2008, Special Issue II, 10-18.

26. Kosinska-Kaczynska K, Szymusik I, Bomba-Opon D, [et al.]. Late prematurity in twins: a Polish multicenter study. Twin Res Hum Genet. 2014, 17 (5), 369-375.

27. Lee YM, Wylie BJ, Simpson LL, [et al.]. Twin chorionicity and the risk of stillbirth. Obstet Gynecol. 2008, 111, 301-308.

28. Johnson CD, Zhang J. Survival of other fetuses after a fetal death in twin or triplet pregnancies. Obstet Gynecol. 2002, 99, 698-703.

29. Danon D, Sekar R, Hack KE, [et al.]. Increased stillbirth in uncomplicated monochorionic twin pregnancies: a systematic review and meta-analysis. Obstet Gynecol. 2013, 121 (6), 1318-1326.

30. Dias T, Patel D, Bhide A, [et al.]. Prospective risk of late stillbirth in monochorionic twins: a regional cohort study. Southwest Thames Obstetric Research Collaborative (STORK). Ultrasound Obstet Gynecol. 2012, 39, 500-504.

31. Dias T, Akolekar R. Timing of birth in multiple pregnancy. Best Pract Res Clin Obstet Gynaecol. 2014, 28 (2), 319-326. 